\title{
Determining Angstrom Constants for Estimating Solar Radiation in Malawi
}

\author{
Griffin Salima1, Geoffrey M. S. Chavula \\ ${ }^{1}$ Department of Mechanical Engineering, University of Malawi-The Polytechnic, Blantyre, Malawi \\ ${ }^{2}$ Department of Civil Engineering, University of Malawi-The Polytechnic, Blantyre, Malawi \\ Email: \{gsalima, gchavula\}@poly.ac.mw
}

Received December 2, 2011; revised January 24, 2012; accepted February 28, 2012

\begin{abstract}
This paper discusses a procedure that was adopted for the development of a linear regression model for estimating solar radiation in Malawi. By making use of sunshine-hours data recorded at six selected meteorological stations in the country, namely: Salima, Makoka, Karonga, Bolero, Chileka and Mzimba over the period 1991-1995, a set of Angstrom constants were obtained and averaged in order to develop the linear regression model. This model has potential for generating ground observation data of solar radiation at any given location in the country using sunshine hours as the only required input. The Gunn-Bellan Spherical Pyranometer and the Campbell Stokes Sunshine Recorder were respectively used in the measurement of incident radiation $\left(\mathrm{I}_{\mathrm{b}}\right)$ in $\mathrm{J} \cdot \mathrm{cm}^{-2} /$ day (converted to $\mathrm{MJ} \cdot \mathrm{m}^{-2} \cdot \mathrm{day}^{-1}$ ) and sunshine hours. An Angstrom model of monthly average Clearness Index with normalized sunshine duration was then developed for each of the six meteorological stations. The resulting linear regression model was applied in estimating monthly average daily solar radiation. Regression analysis between computed and measured radiation data was applied to assess the reliability of the generated Angstrom constants. The results generally show a high degree of agreement between the two variables, with correlation coefficients ranging from 0.63 to 0.90 . Angstrom constants obtained at the six meteorological stations were thereafter averaged in order to develop a linear regression model for estimating solar radiation in Malawi. Solar radiation values obtained using this model were noted to be in good agreement with those developed for each of the six meteorological stations.
\end{abstract}

Keywords: Solar Radiation; Angstrom Constants; Sun-Shine Hours; Attenuation; Linear Regression Model

\section{Introduction}

The need to explore the potential of renewable energy in Malawi cannot be overemphasised. Although the energy sector in the country comprises five main sub-sectors, i.e., electricity, biomass (fuelwood), petroleum products, coal, and other renewable energy sources (Table 1), the country's energy needs are mainly derived from fuelwood, which accounts for $88.5 \%$ of the total energy demand [1]. Hydrocarbon fuels, electricity and coal, respectively supply $6.4 \%, 2.8 \%$, and $2.4 \%$ [2]. The severe deforestation being experienced in the country is a direct result of fuelwood demands and the clearing of vast expanses of land for agricultural production. This has had serious repercussions on soil erosion, frequency and intensity of flash floods, siltation of water bodies, and reduction of greenhouse gas sink capacity.

The country's high dependence on fuelwood calls for concerted effort by all Malawians to explore and exploit alternative sources of energy in order to arrest deforestation, and thus curb further environmental degradation. This study is an attempt at assessing Malawi's potential for developing solar energy as a viable option, noting that the search for alternative energy sources is in line with Malawi Energy Policy and the Malawi Growth and Development Strategy (MDGS).

\section{Solar Energy}

Solar energy is a renewable resource, and is environmentally friendly. Unlike fossil fuels that are only found in selected regions of the world (e.g., in OPEC countries, the Gulf of Mexico, etc.), solar energy is available just about everywhere on earth. The added advantage of solar energy is that it is provided for free and is not susceptible to price fluctuations associated with fossil fuels. Solar radiation may be harnessed for use either as solar thermal or photovoltaic.

The main source of solar energy is the sun. This celestial body emits electromagnetic energy determined by solar output, sun-earth positioning, latitude, time of the year and time of the day. Between the top of the atmosphere and the earth's surface, the incident radiation from 
Table 1. Energy mix in Malawi in 2002 and 2009 ([1,2]).

\begin{tabular}{cccc}
\hline \multirow{2}{*}{ Energy Source } & \multicolumn{2}{c}{ Percentage Contribution } & Estimates \\
\cline { 2 - 4 } & 2002 & 2009 & 2010 \\
\hline Biomass & 93 & 88.4 & 84.1 \\
Electricity & 2.3 & 2.7 & 8.0 \\
Hydrocarbon Fuels & 3.5 & 6.3 & 5.5 \\
$\quad$ Coal & 1.0 & 2.3 & 2.0 \\
$\begin{array}{c}\text { Renewable and } \\
\text { Alternative Sources }\end{array}$ & 0.2 & 0.3 & 0.4 \\
\hline
\end{tabular}

the sun experiences attenuation caused by water vapour and gaseous and dust particles, through reflection, absorption and scattering. The solar flux at the earth's surface is given as the sum of incident and diffuse radiation.

Global solar radiation $\mathrm{H}_{\mathrm{h}}$ may be represented by the following expression [3]:

$$
\mathrm{H}_{\mathrm{h}}=\mathrm{K}_{\mathrm{T}} \mathrm{H}_{\mathrm{o}}
$$

where $\mathrm{K}_{\mathrm{T}}$ is the Clearness Index (i.e., the degree of transparency of the atmosphere to the passage of solar radiation) and $\mathrm{H}_{\mathrm{o}}$ is the extraterrestrial solar radiation on a horizontal surface. $\mathrm{H}_{\mathrm{o}}$ is only a function of latitude and is independent of other location-specific parameters. The daily clearness index $\mathrm{K}_{\mathrm{T}}$ is also given as $\mathrm{H}_{\mathrm{h}} / \mathrm{H}_{0}$, i.e., ratio of the daily global radiation on a horizontal surface to the daily extraterrestrial radiation on a horizontal surface. Because of attenuation, $\mathrm{H}_{\mathrm{h}}$ is very much dependent on the location of the place on the earth's surface; and its value is less than extraterrestrial irradiation, $\mathrm{H}_{0}$.

Various climate models have been developed for use in predicting the monthly average global solar radiation, the popular one being the Angstrom-type regression equation developed by Angstrom in 1924 [4], This relates monthly average daily global radiation to the average daily sunshine hours, and is given by the following expression:

$$
\frac{\mathrm{H}_{\mathrm{h}}}{\mathrm{H}_{\mathrm{o}}}=\mathrm{a}+\mathrm{b} \frac{\mathrm{n}}{\mathrm{N}}
$$

where: $H_{h}$ is the monthly average daily global radiation on a horizontal surface $\left(\mathrm{MJ} \cdot \mathrm{m}^{-2} \cdot\right.$ day $\left.^{-1}\right), \mathrm{H}_{\mathrm{o}}$ is the monthly average daily extraterrestrial radiation on a horizontal surface $\left(\mathrm{MJ} \cdot \mathrm{m}^{-2} \cdot \mathrm{day}^{-1}\right), \mathrm{n}$ is the monthly average daily number of hours of bright sunshine, $\mathrm{N}$ is the monthly average daily maximum number of hours of possible sunshine (or day length), and a and $\mathrm{b}$ are regression constants. Equation (2) has been noted to predict global solar radiation in several locations on earth with a high degree of accuracy.

The extraterrestrial solar radiation on a horizontal surface is calculated from the following Equation (3):

$$
\begin{aligned}
\mathrm{H}_{\mathrm{o}}= & \frac{24 \times 3.6 \times 10^{-3} \times \mathrm{I}_{\mathrm{SC}}}{\pi} \\
& \times\left(1+0.033 \cos \left(360 \frac{\mathrm{d}}{365}\right)\right) \cos \phi \cos \delta \sin \omega \\
& +\omega \sin \phi \sin \delta
\end{aligned}
$$

where $d$ is the Julian day number, $\mathrm{I}_{\mathrm{SC}}$ is the solar constant with a value of $1367 \mathrm{Wm}^{-2}, \phi$ is the latitude of the location, $\delta$ is the declination angle:

$$
\delta=23.45 \sin \left(360 \frac{248+\mathrm{d}}{365}\right)
$$

and $\omega$ is the sunset hour angle:

$$
\omega=\cos ^{-1}(-\tan \phi \tan \delta)
$$

The maximum possible sunshine duration $\mathrm{N}$ is given by:

$$
\mathrm{N}=\left(\frac{2}{15}\right) \omega
$$

Solar energy may be harnessed and used for various purposes including domestic use such as cooking, heating, and lighting.

Major studies on solar radiation in Malawi include those done by Som [5], Zingano ([6,7]), Madhlopa ([8,9]) and Salima [10]. Som [5] showed that Malawi has potential for harnessing solar radiation for domestic heating. Zingano $([6,7])$ studied the intensity of global radiation for twelve selected sites in Malawi based on sunshine duration. He observed that lowlands have higher values of global solar radiation than uplands. Madhlopa [8] evaluated piecewise polynomial models for estimating diffuse radiation at Makoka Research Station in Zomba District (Malawi). Salima [10] investigated the spatial and temporal distribution of solar radiation in Malawi and the potential for harnessing it for domestic use. On a continental scale, Diabaté [11] created a map of solar radiation for Africa using Clearness Index for 62 selected sites, but these stations did not include those from Malawi.

\section{Objective of the Study}

The main objective of the study was to develop a linear regression model for use in estimating solar radiation in Malawi.

\section{Methodology}

In order to determine the value of $\mathrm{H}_{\mathrm{h}}$ in Equation (2), sunshine-hours data recorded over the period 1991-1995 was collected from six selected meteorological stations, namely: Salima, Makoka, Karonga, Bolero, Chileka and Mzimba using the Camp-Bell Stokes Sunshine Recorder (Figure 1 and Table 2). Data on incident $\left(\mathrm{I}_{\mathrm{b}}\right)$ in $\mathrm{J} \cdot \mathrm{cm}^{-2} /$ day 


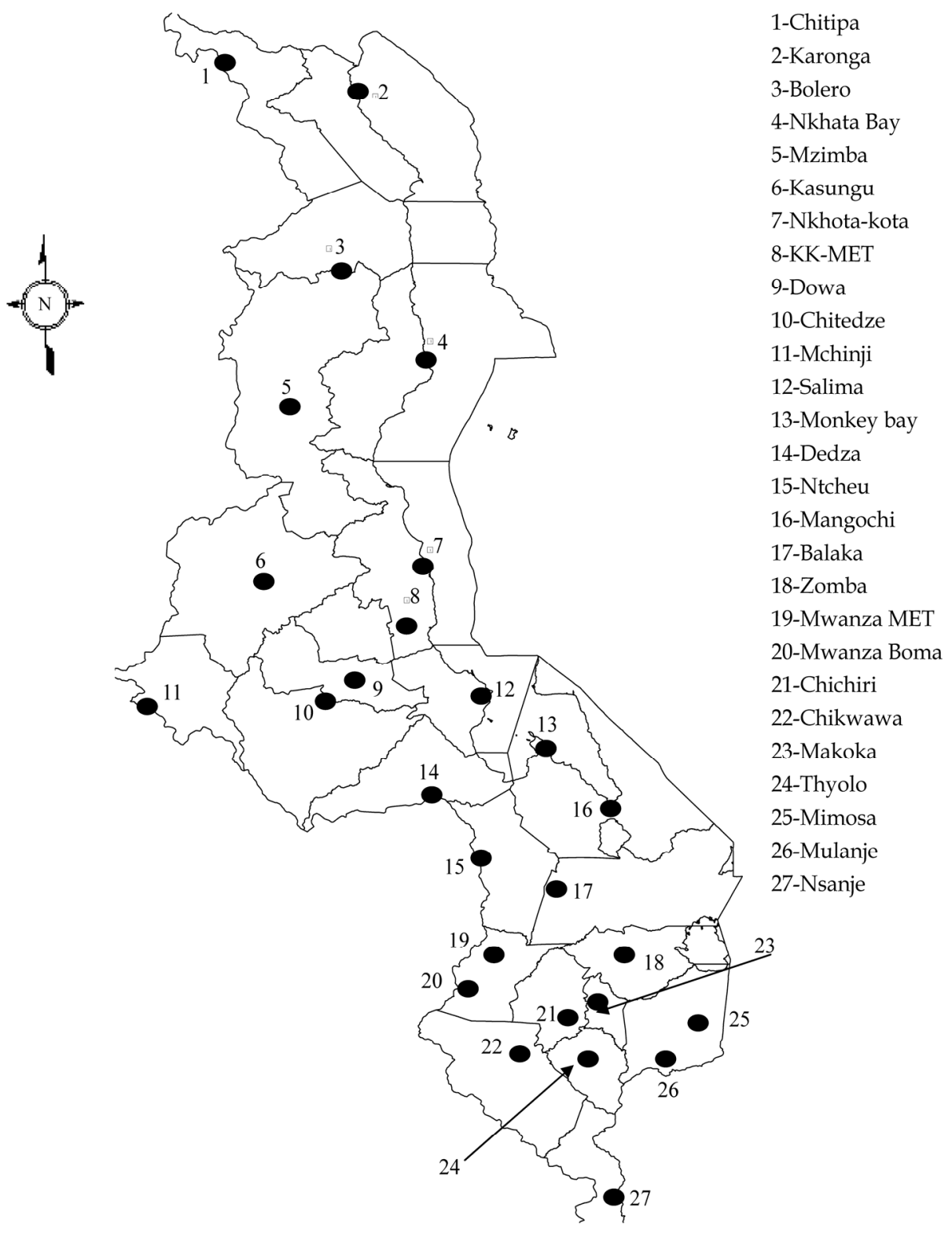

Figure 1. Some of the meteorological stations in Malawi.

Table 2. Location of the six selected meteorological stations.

\begin{tabular}{cccc}
\hline Station name & $\begin{array}{c}\text { Latitude } \\
\text { (south) }\end{array}$ & $\begin{array}{c}\text { Longtude } \\
\text { (east) }\end{array}$ & $\begin{array}{c}\text { Altitude } \\
\text { (m) }\end{array}$ \\
\hline Bolero & $11^{\circ} 4^{\prime}$ & $33^{\circ} 47^{\prime}$ & 1100 \\
Karonga & $09^{\circ} 57^{\prime}$ & $33^{\circ} 53^{\prime}$ & 529 \\
Mzimba & $11^{\circ} 53^{\prime}$ & $33^{\circ} 37^{\prime}$ & 1349 \\
Salima & $12^{\circ} 45^{\prime}$ & $34^{\circ} 35^{\prime}$ & 512 \\
Makoka & $15^{\circ} 31^{\prime}$ & $35^{\circ} 13^{\prime}$ & 1029 \\
Chileka & $15^{\circ} 41^{\prime}$ & $34^{\circ} 35^{\prime}$ & 767 \\
\hline
\end{tabular}

(converted to $\mathrm{MJ} \cdot \mathrm{m}^{-2} \cdot \mathrm{day}^{-1}$ ) radiation was collected by the Gunn-Bellan Spherical Pyranometer. An Angstrom model of monthly average Clearness Index with normal- ized sunshine duration was then developed for each of the six meteorological stations.

Values of $\mathrm{H}_{\mathrm{o}}$ and $\mathrm{N}$ were calculated for each month using Equations (3) and (6), respectively. The regression coefficients $a$ and $b$ in Equation (2) were computed from a graphical plot of $\mathrm{H}_{\mathrm{h}} / \mathrm{H}_{\mathrm{o}}$ and $\mathrm{n} / \mathrm{N}$, with a as the intercept on the $\mathrm{H}_{\mathrm{h}} / \mathrm{H}_{\mathrm{o}}$ axis and $\mathrm{b}$ as the gradient.

Differences between estimated and measured values of solar radiation were determined by the Mean Bias Error (MBE), the Root Mean Square Error (RMSE), and the Mean Percentage Error (MPE), given by the following respective expressions:

Mean bias error $(\mathrm{MBE})=\left[\sum\left(\mathrm{H}_{\mathrm{h}(\text { cal })}-\mathrm{H}_{\mathrm{h}(\text { meas })}\right)\right] / \mathrm{m}$ 
Root Mean Square Error (RMSE)

$$
=\sqrt{\frac{\sum\left(\mathrm{H}_{\mathrm{h}(\text { cal })}-\mathrm{H}_{\mathrm{h}(\text { meas })}\right)^{2}}{\mathrm{~m}}}
$$

\section{Results and Discussion}

Results of data analysis showed that maximum and minimum solar radiation values were observed in October and January, respectively.

Values of regression constants of Equation (2), along with the correlation coefficients (RC) and the values of the MBE, RMSE and MPE for the six meteorological stations are summarized in Table 3. Figure 2 shows the spatial distribution of sun hours in Malawi.

Results presented in Table 3 show that regression coefficients (RC) are higher than 0.60 , implying a good fitting between the Clearness Index $\mathrm{H}_{\mathrm{h}} / \mathrm{H}_{\mathrm{o}}$ and the relative possible number of sunshine hours $\mathrm{n} / \mathrm{N}$. Furthermore, there is a remarkable agreement between the measured and calculated values of global radiation for the six locations as attested by very low values of RMSE and MPE. Negative and positive values of MPE respectively show slight overestimation and underestimation of $\mathrm{H}_{\mathrm{h}}$.

Comparison between measured and calculated $\mathrm{H}_{\mathrm{h}}$ using Equation (2), along with regression constants given in Table 3, indicate that the percentage error for a single month rarely exceeds $\pm 2 \%$ at any of the six meteorological stations. For example, the calculated annual average daily solar radiation value at Salima using Equation (2) is $22.1 \mathrm{MJ} / \mathrm{m}^{-2} \cdot$ day $^{-1}$ while the measured value is 21.6 $\mathrm{MJ} / \mathrm{m}^{-2}$. day $^{-1}$. The corresponding values for Karonga and Chileka are $17.69 \mathrm{MJ} / \mathrm{m}^{-2} \cdot$ day $^{-1}$ and $17.7 \mathrm{MJ} / \mathrm{m}^{-2}$. day $^{-1}$, and $20.81 \mathrm{MJ} / \mathrm{m}^{-2}$. day ${ }^{-1}$ and $20.9 \mathrm{MJ} / \mathrm{m}^{-2}$. day ${ }^{-1}$, respectively. Table 4 gives a summary of global and diffuse radiation for Mzimba, Karonga, Makoka, Bolero and Salima meteorological stations.

From the results highlighted in Table 3, the following simple first order Angstrom correlations models may be developed for use in estimating values of $\mathrm{H}_{\mathrm{h}}$ at each of the respective six meteorological stations:

1) Salima

$$
\frac{\mathrm{H}_{\mathrm{h}}}{\mathrm{H}_{\mathrm{o}}}=0.20+0.44 \frac{\mathrm{n}}{\mathrm{N}}
$$

2) Makoka

$$
\frac{\mathrm{H}_{\mathrm{h}}}{\mathrm{H}_{\mathrm{o}}}=0.30+0.39 \frac{\mathrm{n}}{\mathrm{N}}
$$

3) Karonga

$$
\frac{\mathrm{H}_{\mathrm{h}}}{\mathrm{H}_{\mathrm{o}}}=0.31+0.44 \frac{\mathrm{n}}{\mathrm{N}}
$$

4) Bolero

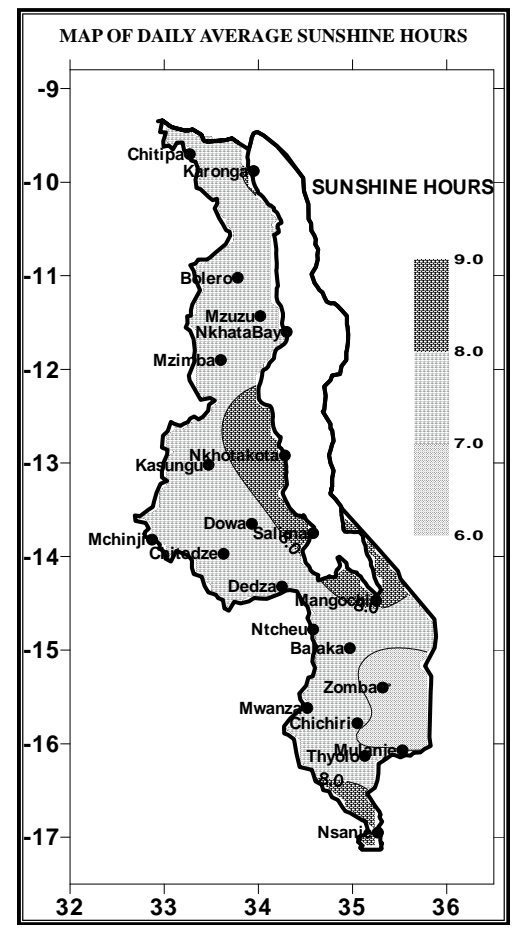

Figure 2. Sunshine hour map for Malawi.

$$
\frac{\mathrm{H}_{\mathrm{h}}}{\mathrm{H}_{\mathrm{o}}}=0.36+0.36 \frac{\mathrm{n}}{\mathrm{N}}
$$

5) Mzimba

$$
\frac{\mathrm{H}_{\mathrm{h}}}{\mathrm{H}_{\mathrm{o}}}=0.29+0.39 \frac{\mathrm{n}}{\mathrm{N}}
$$

6) Chileka

$$
\frac{\mathrm{H}_{\mathrm{h}}}{\mathrm{H}_{\mathrm{o}}}=0.32+0.27 \frac{\mathrm{n}}{\mathrm{N}}
$$

It is apparent from Equations (10)-(15) that neither a nor $b$ vary with latitude or altitude in any systematic manner. However, the values of the sum of the regression constants $\mathrm{a}+\mathrm{b}$, which represent the maximum Clearness Index $((n / N)=1)$, averaged over the period of analysis, are found to be almost equal for the six meteorological stations. The values of $(\mathrm{a}+\mathrm{b})$ obtained for Salima, Karonga, Bolero, Mzimba, Makoka, and Chileka are 0.69, $0.72,0.59,0.58,0.68$ and 0.59 , respectively.

Averaged results for linear regression models for the six selected stations were used in developing the linear regression model for estimating solar radiation in Malawi:

$$
\frac{\mathrm{H}_{\mathrm{h}}}{\mathrm{H}_{\mathrm{o}}}=0.29+0.38 \frac{\mathrm{n}}{\mathrm{N}}
$$

Equation (16) was then used in estimating $\mathrm{H}_{\mathrm{h}}$ for the six locations, and in all cases the Mean Percentage Error did not exceed $\pm 10 \%$. This is indicative of a fairly good 
Table 3. Regression constants of Equation (2) for the selected locations and the corresponding values of RC, MBE, RMSE and MPE.

\begin{tabular}{|c|c|c|c|c|c|c|c|}
\hline \multirow{2}{*}{ Location } & \multirow{2}{*}{ Degree of correlation RC } & \multicolumn{3}{|c|}{ Regression constants } & \multirow{2}{*}{ MBE } & \multirow{2}{*}{ RMSE } & \multirow{2}{*}{ MPE $(\%)$} \\
\hline & & $\mathrm{a}$ & $\mathrm{b}$ & $(a+b)$ & & & \\
\hline Salima & 0.90 & 0.32 & 0.37 & 0.69 & -0.015 & 1.72 & -0.43 \\
\hline Karonga & 0.83 & 0.31 & 0.41 & 0.72 & -0.037 & 0.328 & 0.176 \\
\hline Bolero & 0.63 & 0.37 & 0.22 & 0.59 & -0.035 & 0.742 & 0.037 \\
\hline Mzimba & 0.71 & 0.33 & 0.25 & 0.58 & 0.908 & 0.668 & -0.254 \\
\hline Makoka & 0.74 & 0.33 & 0.35 & 0.68 & -0.041 & 1.457 & -0.264 \\
\hline Chileka & 0.84 & 0.32 & 0.27 & 0.59 & -0.060 & 0.467 & 0.235 \\
\hline
\end{tabular}

Table 4. Monthly global and diffuse radiation for the reference stations.

\begin{tabular}{ccccccccccc}
\hline & MZIMBA & ST. & KARONGA & ST. & MAKOKA & ST. & BOLERO & ST. & SALIMA & ST. \\
\hline Month & $\mathbf{H}_{\mathbf{h}}$ & $\mathbf{H}_{\mathbf{d}}$ & $\mathbf{H}_{\mathbf{h}}$ & $\mathbf{H}_{\mathbf{d}}$ & $\mathbf{H}_{\mathbf{h}}$ & $\mathbf{H}_{\mathbf{d}}$ & $\mathbf{H}_{\mathbf{h}}$ & $\mathbf{H}_{\mathbf{d}}$ & $\mathbf{H}_{\mathbf{h}}$ & $\mathbf{H}_{\mathbf{d}}$ \\
\hline Jan & 17.86 & 12.37 & 20.2 & 11.95 & 20.8 & 12.31 & 18.69 & 12.26 & 15.28 & 11.99 \\
Feb & 17.45 & 12.19 & 20.7 & 11.9 & 20 & 12.49 & 20.13 & 11.91 & 19.98 & 11.49 \\
Mar & 26.41 & 6.12 & 20.8 & 11.61 & 18.9 & 12.7 & 18.75 & 12.01 & 20.33 & 10.99 \\
Apr & 22.79 & 6.8 & 19 & 12.17 & 17.2 & 12.57 & 19.85 & 9.32 & 21.61 & 7.27 \\
May & 9.95 & 8.44 & 19.7 & 11.98 & 17.1 & 12.5 & 20.67 & 5.71 & 20.49 & 4.83 \\
Jun & 15.8 & 8.04 & 19.2 & 11.99 & 16 & 12.35 & 18.67 & 6.28 & 19.5 & 4.6 \\
Jul & 19.58 & 5.65 & 20.3 & 12.01 & 16.9 & 12.59 & 20.72 & 5.73 & 19.24 & 5.32 \\
Aug & 18.23 & 9.02 & 24.1 & 9.97 & 20 & 12.49 & 19.87 & 8.22 & 20.79 & 6.58 \\
Sep & 22.27 & 8.83 & 26.2 & 8.29 & 23.8 & 11.17 & 21.03 & 9.87 & 22.43 & 8.42 \\
Oct & 22.44 & 10.49 & 27.4 & 7.02 & 25.2 & 9.94 & 21.47 & 10.85 & 23.47 & 9.7 \\
Nov & 12.17 & 10.61 & 26.4 & 7.83 & 23.7 & 11.12 & 20.18 & 11.94 & 23.74 & 10.71 \\
Dec & 19.83 & 12.19 & 23 & 10.8 & 19.9 & 12.43 & 21.27 & 11.5 & 22.82 & 11.53 \\
\hline
\end{tabular}

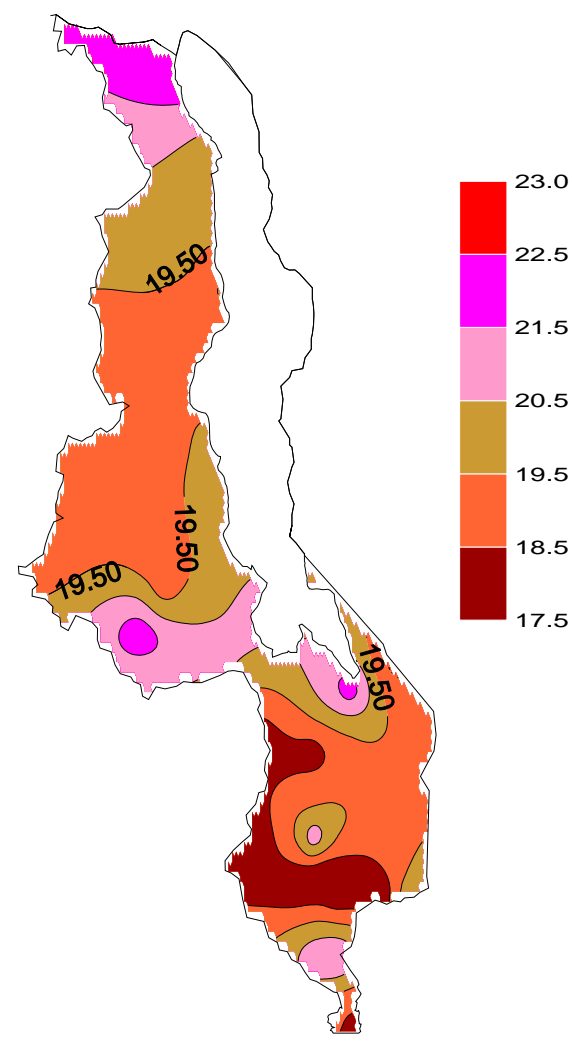

Figure 3. Average daily distribution of solar radiation in malawi in $\mathbf{M J} / \mathrm{m}^{-2} \cdot \mathrm{day}^{-1}$. agreement between measured and calculated global radiation for all the meteorological stations. Figures 3 and 4 show Daily and monthly distribution of solar radiation in Malawi developed from Equation (16).

\section{Conclusions}

The study has shown that maximum and minimum solar radiation in Malawi take place in October and January respectively. Therefore the optimum time for using solar energy is during the month of October.

The study also resulted in the development of respective Angstrom linear regression models for each of the six selected meteorological stations, which culminated in the development of the Angstrom model for Malawi given by Equation (16).

A fairly good agreement (MPE $\leq \pm 10 \%$ ) was noted between measured values and calculated values of solar radiation at the six selected meteorological stations, which makes Equation (16) useful for estimating solar radiation in Malawi.

Since knowledge of the amount of irradiance reaching any point on the earth's surface is critical in the design solar systems, the model we have developed may help the Malawi Government to develop realistic energy policies and programmes based on sound scientific knowledge.

In Malawi, where there is abundant sunlight and a 

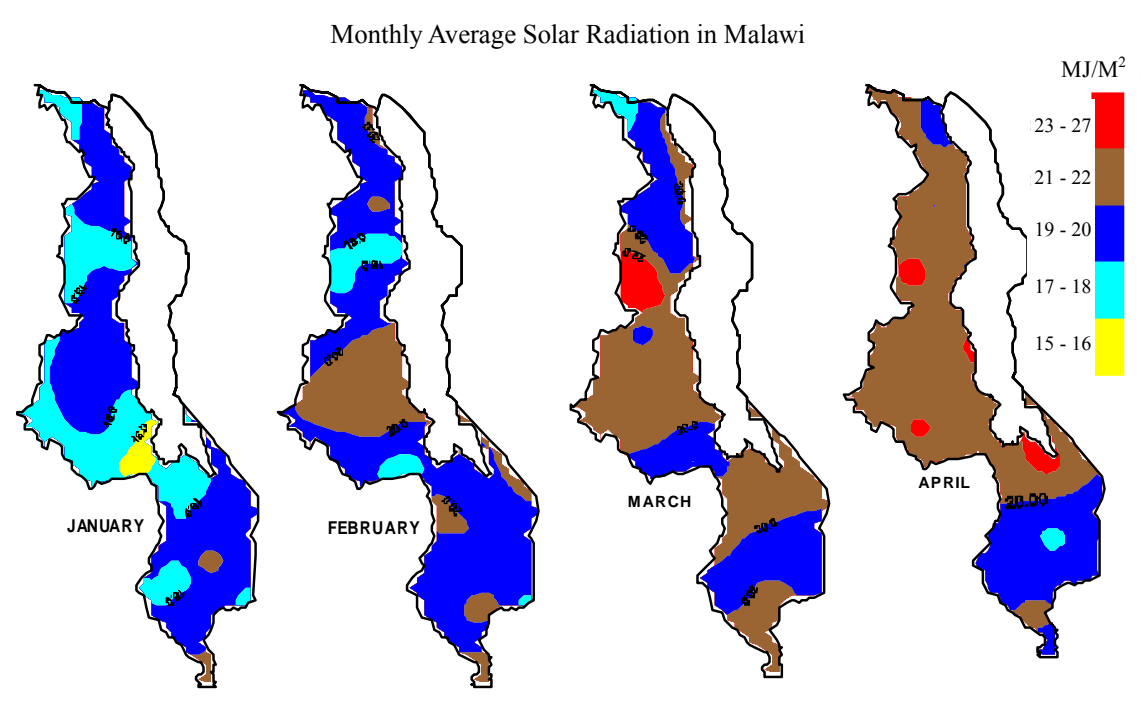

(a)

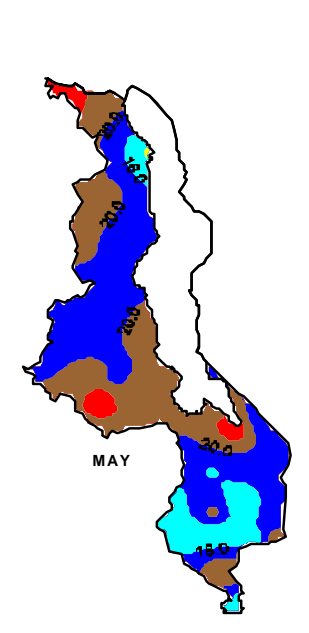

Monthly Average Solar Radiation in Malawi

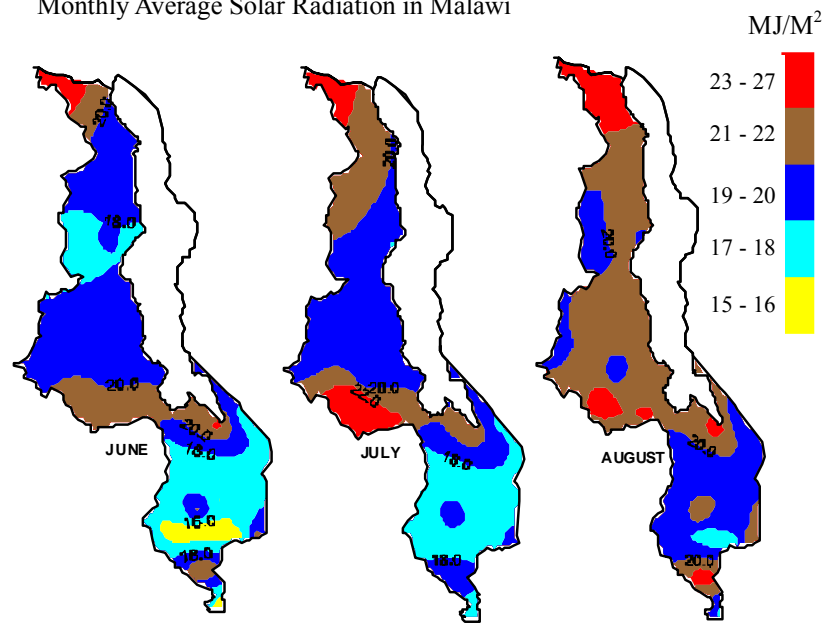

(b)

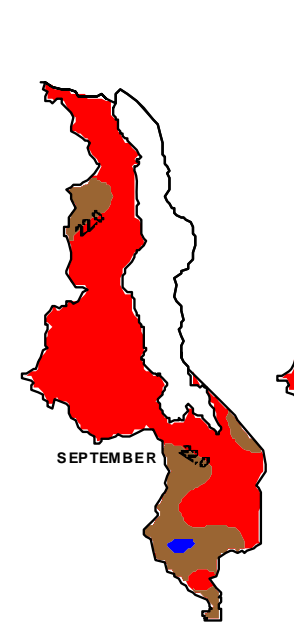

Monthly Average Solar Radiation in Malawi
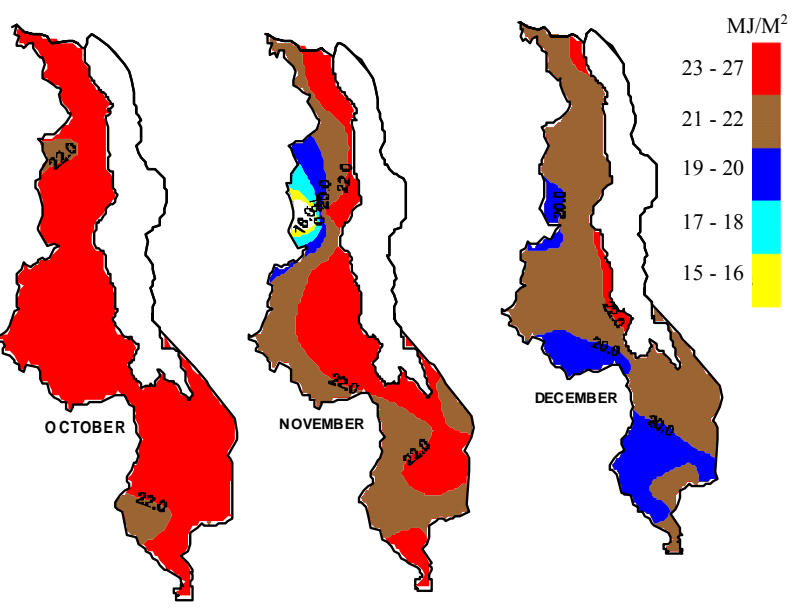

(c)

Figure 4. (a) Monthly distribution of solar radiation in Malawi; (b) Monthly distribution of solar radiation in Malawi; (c) Monthly distribution of solar radiation in Malawi. 
large rural population without proper infrastructure to develop an electricity grid, use of PV is seen as an attractive option because of its modular features, namely: its ability to generate electricity at the point of use, its low maintenance requirements and its non-polluting characteristics.

\section{REFERENCES}

[1] Government of Malawi, "Malawi Biomass Energy Strategy," Department of Energy, Lilongwe, 2009.

[2] Government of Malawi, "Malawi State of Environment and Outlook: Environment for Sustainable Economic Growth," Malawi Government, 2010.

[3] J. A. Duffie and W. A. Beckman, "Solar Engineering of Thermal Processes," 2nd Edition, John Wiley, New York, 1994.

[4] A. Angstrom, "Solar and Terrestrial Radiation," Quarterly Journal of the Royal Meteorological Society, Vol. 50, No. 210,1924 , pp. 121-125. doi: 10.1002/qi.49705021008

[5] A. K. Som, "Solar Utilization Potential in Malawi," Malawi Journal of Science, Vol. 3, 1979, pp. 103-104.
[6] B. Zingano, "An Appraisal for Solar Water Heating in Malawi," MSc. Thesis, University of Malawi, Zomba, 1986.

[7] B. Zingano, "A Discussion on Thermal Comfort with Reference to Bath Water Temperature to Deduce a Midpoint of the Thermal Comfort Zone," Renewable Energy, Vol. 23, 2001, pp. 41-47.

[8] A. Madhlopa, "Evaluation of Piecewise Polynomial Models for Computation of Daily Diffuse Radiation in Malawi," Proceedings of the 2001 ISES Solar World Congress, 2001, pp. 2183-2189.

[9] A. Madhlopa, "Solar Radiation Climate in Malawi," Solar Energy, Science Direct, University of Malawi, Zomba, 2005.

[10] S. Griffin, "Spatial and Temporal Solar Radiation Distribution and Solar Energy Collection Potential in Malawi," M.Sc. Dissertation, University of Zimbabwe, Harare, 2007.

[11] L. Diabate, Ph. Blanc and L. Wald, "Solar Climate in Africa," Solar Energy, Vol. 76, No. 6, 2004, pp. 733-744. doi:10.1016/j.solener.2004.01.002 